\title{
NUMERICAL ANALYSIS ON PERFORMANCE CHARACTERISTICS OF A MICROCHANNEL HEAT EXCHANGER WHEN RECTANGULAR FINS ARE REPLACED WITH TRIANGULAR FINS
}

\author{
Jayasree Bethapudi \\ Department of Mechanical Engineering (Thermal Engineering) \\ Sreenidhi Institute of Science and Technology, Yamnampet, Ghatkesar, Telangana
}

\begin{abstract}
Microchannels are being used in many fields like heating, ventilation, air conditioning and refrigeration, automobiles, biomedical mechanical applications etc. When there are various shapes of microchannels like rectangle, straight channel, segmented, cylindrical, triangle, square are available, most of the manufacturers desire to use rectangle shape as they are simple in design and easy to manufacture. In this study we are comparing the rectangular shape to triangular shape and see which is beneficial for a manufacturer by analyzing their performance characteristics using some parameters like heat flux ranging from $100-500 \mathrm{kw} / \mathrm{m} 2$, temperature ranging from 100-500K and Reynolds number ranging from 100-500. The work is done using ANSYS software which delivers product modeling solutions with unmatched scalability.
\end{abstract}

Keywords-Microchannel heat exchanger, Triangular fins, Rectangular fins

\section{INTRODUCTION}

A Microchannel Heat Exchanger is a sort of cooling arrangement that has been proposed to improve heat dissemination from electric gadgets. As difficulties have been raised to expel the impressive warmth from a restricted space, these miniaturized scale channels came into picture. This microchannel heat sink was initially introduced by Tuckerman and Pease in 1981.

Microchannel Heat Exchanger

These are heat exchangers where liquid streams in even controls with normal estimations underneath $1 \mathrm{~mm}$. These can be made using metal, stoneware.

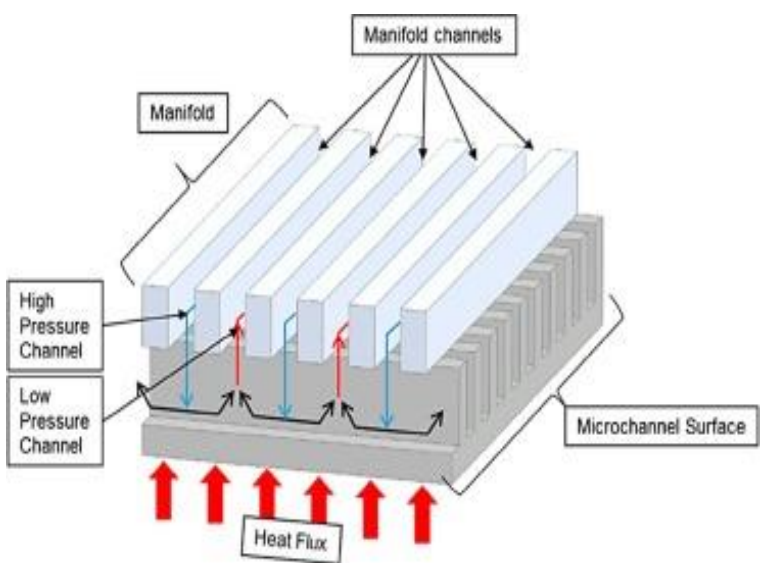

Figure No. 01: Microchannel Heat Exchanger.

A microchannel is a kind of cooling course of action that has been proposed to improve heat dispersal from electronic contraptions. As challenges have been raised to remove the amazing warmth from a confined space, these scaled down scale channels came into the image. This scaled down scale redirects are organized in various shapes like square shape, tube-molded, separated, straight channel, round, considering the need and the space open.

\section{Methodology}

\section{SPECIFICATIONS}

The work is done using the $\mathrm{PC}$ with specifications as below:

$\begin{array}{ll}\text { Processor } & : \text { Intel i3-9100F }-3.60 \mathrm{GHz} \\ \text { RAM } & : 4 \mathrm{~GB} \\ \text { OS } & : \text { Windows } 10 \times 64 \\ \text { ANSYS Version } & : 2020 \mathrm{R} 1\end{array}$

Here, we designed a microchannel heat exchanger with triangular fins and compared it with the microchannel heat exchanger with rectangular fins. 


\section{International Journal of Engineering Applied Sciences and Technology, 2020 \\ Vol. 5, Issue 4, ISSN No. 2455-2143, Pages 310-318 \\ Published Online August 2020 in IJEAST (http://www.ijeast.com)}

\section{GEOMETRY}

A microchannel heat exchanger with triangular fins is considered for our experiment whose dimensions are,

Length: $1.5 \mathrm{~mm}$

Height: $1.1 \mathrm{~mm}$

Angle of triangle: 63.068(Degrees)

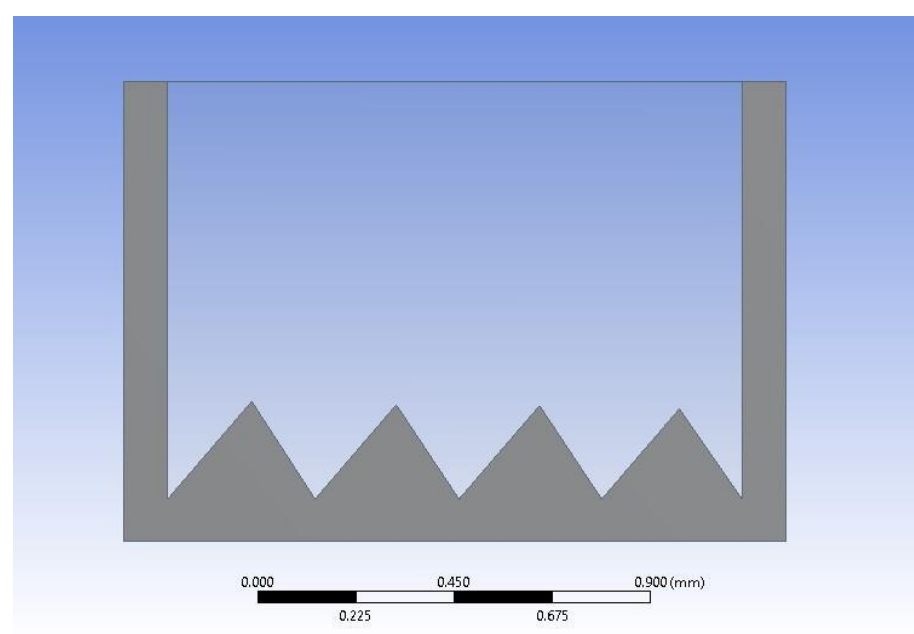

Figure No.02: Micro-channel Heat Exchanger with triangular fins.

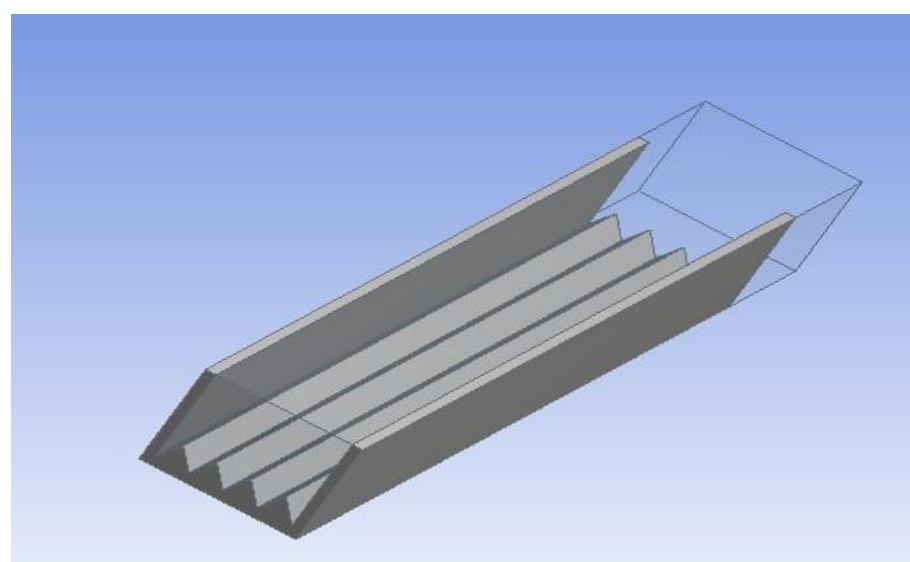

Figure No.03: Isometric view of Micro-channel Heat Exchanger with triangular fins.

\section{MESHING}

Grid independence test has been done for three values of mesh to get the optimum size. The three sizes are $0.0005 \mathrm{~m}$, $0.0003 \mathrm{~m}, 0.0001 \mathrm{~m}$ and we considered the maximum size of $0.0001 \mathrm{~m}$ as it gives 237071 number of elements and 126442 number of nodes.

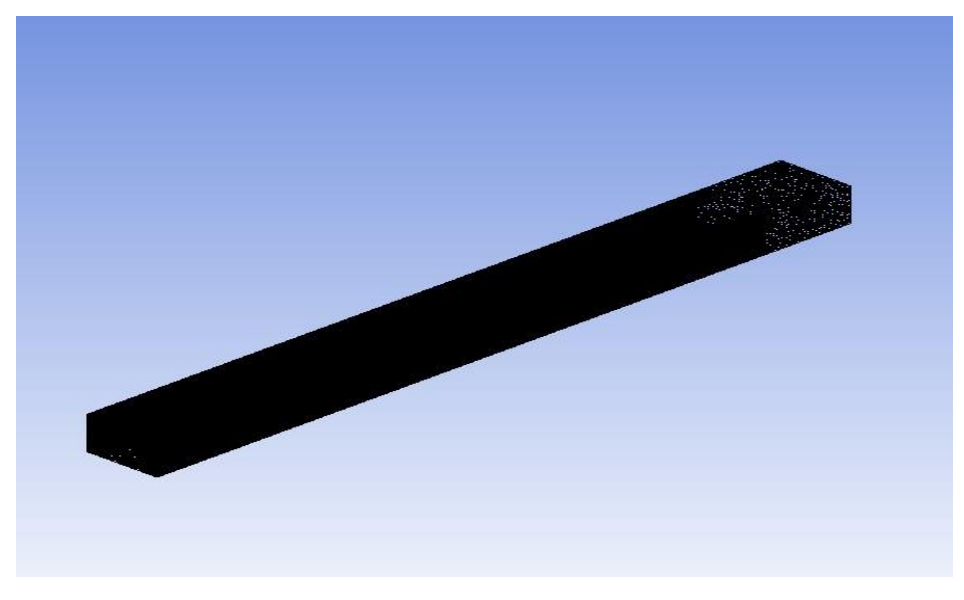

FigureNo.04: Meshing.

\section{BOUNDARY CONDITIONS}

For the process the boundary conditions considered are uniform heat flux at bottom wall(100-500kw/m2), inlet temperature as $303 \mathrm{~K}$ and Reynolds numbers ranging between 100-500. For conducting experiment, the material we choose should be lighter in weight and have good thermal conductivity. We have chosen copper. Once the setup is done and solution is initialized, and we attained the result as shown below, we can observe different colours depending on temperature range.

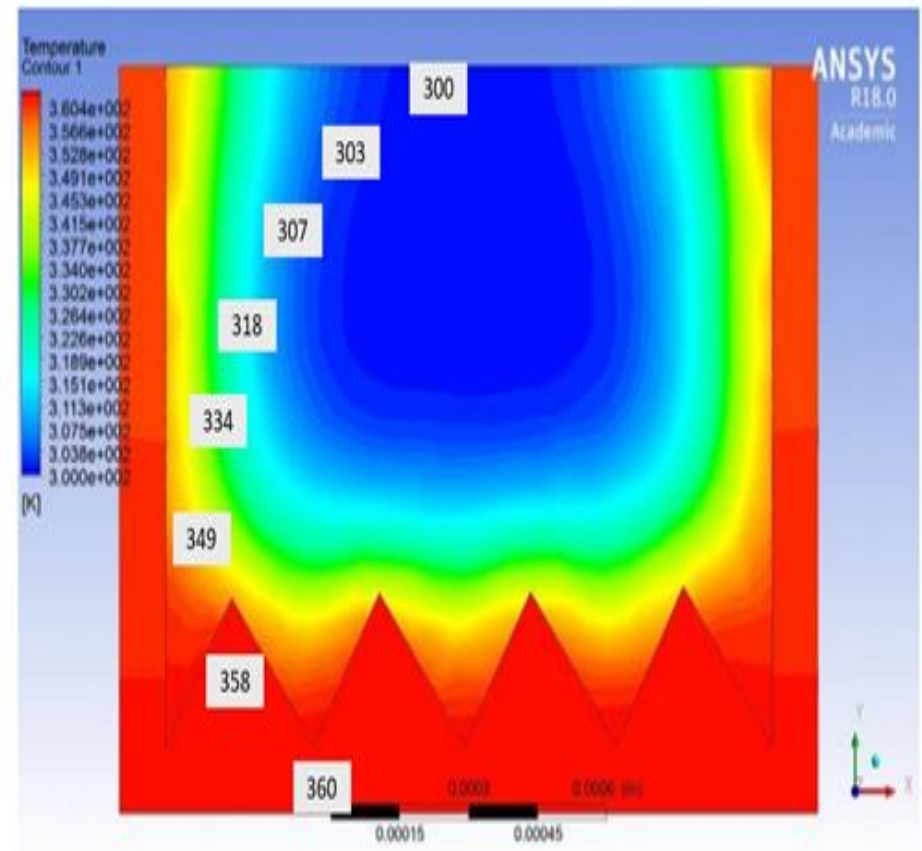

Figure No.05: Temperature contour of the microchannel Heat Exchanger. 


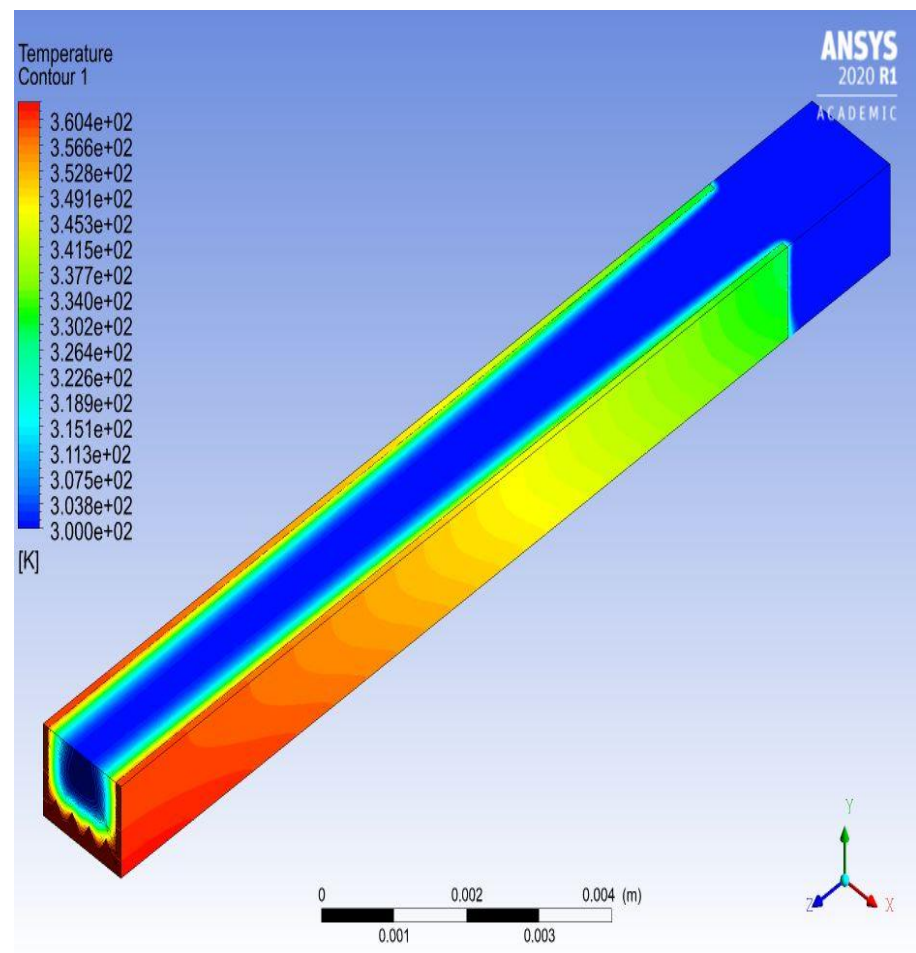

FigureNo.06: Isometric view of Temperature Contour.

The above figures $(5,6)$ show us how the model has its temperature contour in different views. We observe different colours that looks like rainbow colours based on the different ranges of temperatures. Two main colours which show us the difference in temperature range are blue and red where blue shows the lowest temperature and red shows the highest temperature. Here, we obtained the minimum temperature at $300 \mathrm{k}$ and maximum temperature at $360 \mathrm{k}$.

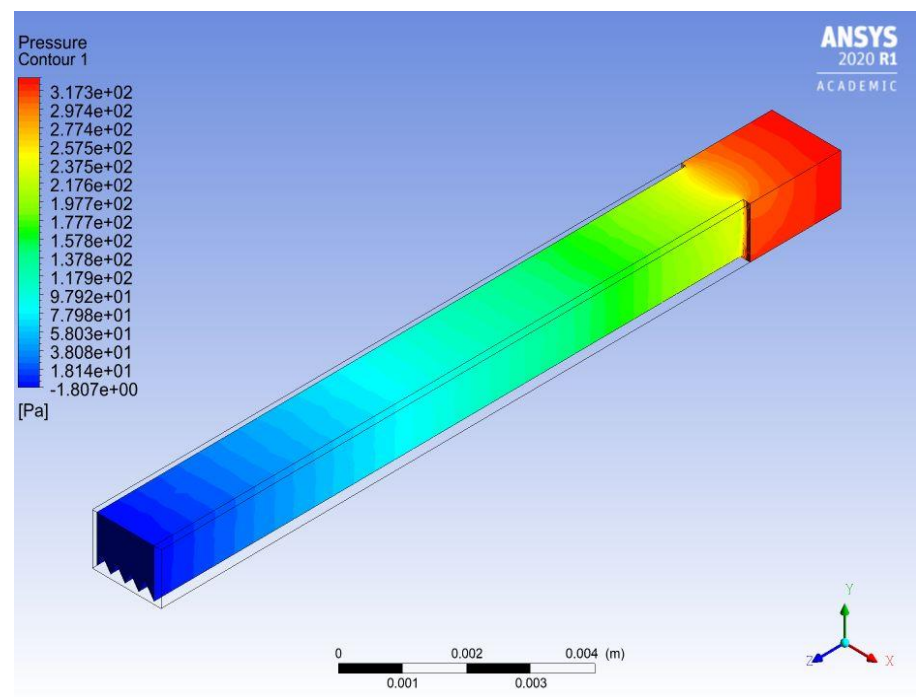

Figure No. 07: Isometric view of Pressure contour.
This is the isometric view of the model that shows us how the pressure is varying through the domain of the microchannel heat exchanger in different colours. Blue colour shows us the minimum pressure and red colour shows us the maximum pressure.

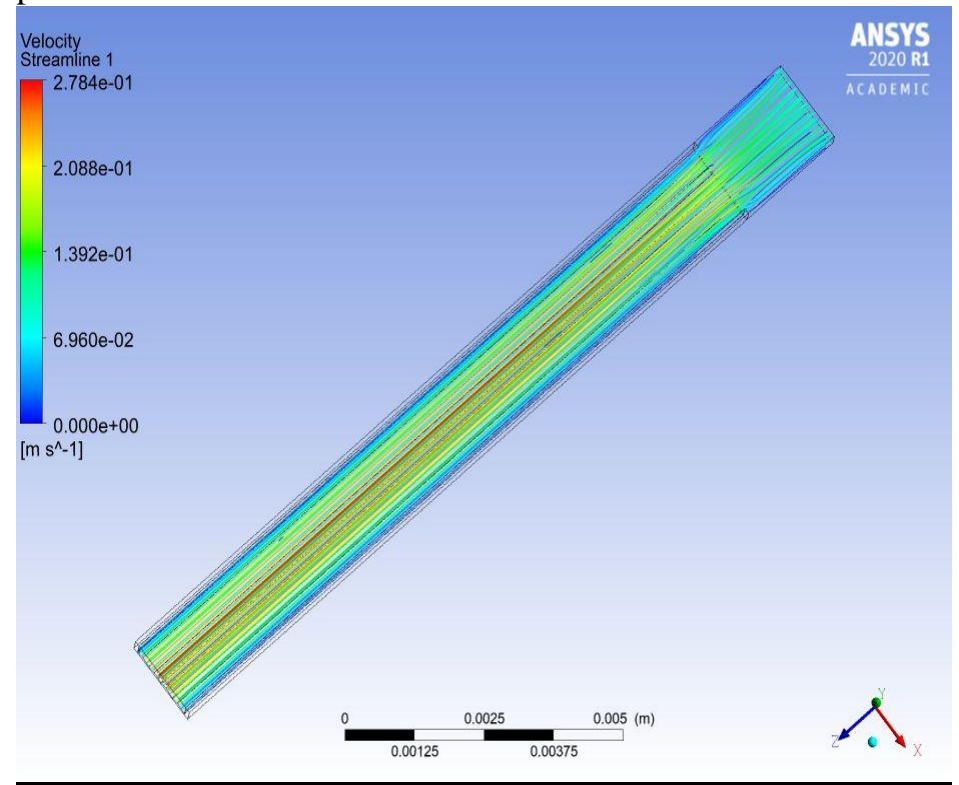

Figure No. 08: Top view of Streamlines.

We can observe the streamlines through the microchannel heat exchanger from the above figure. A streamline is a path which is traced out by a massless particle as it moves with the flow and it can be defined as an imaginary line in the flow field. These streamlines are useful for us in analysing flow.

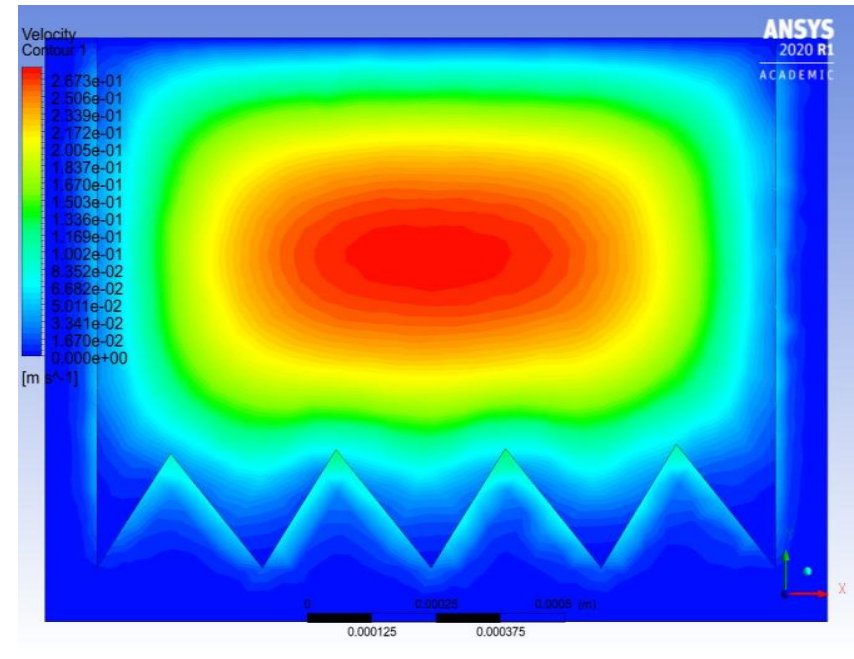

Figure No.09: Velocity.

We can see the velocity variation through the domain of the microchannel heat exchanger. To define the flow velocity, we 


\section{International Journal of Engineering Applied Sciences and Technology, 2020 \\ Vol. 5, Issue 4, ISSN No. 2455-2143, Pages 310-318 \\ Published Online August 2020 in IJEAST (http://www.ijeast.com)}

use different velocity inlet boundary conditions. In our experiment we used the velocities of $0.05,0.10,0.17,0.21,0.26 \mathrm{~m} / \mathrm{s}$.

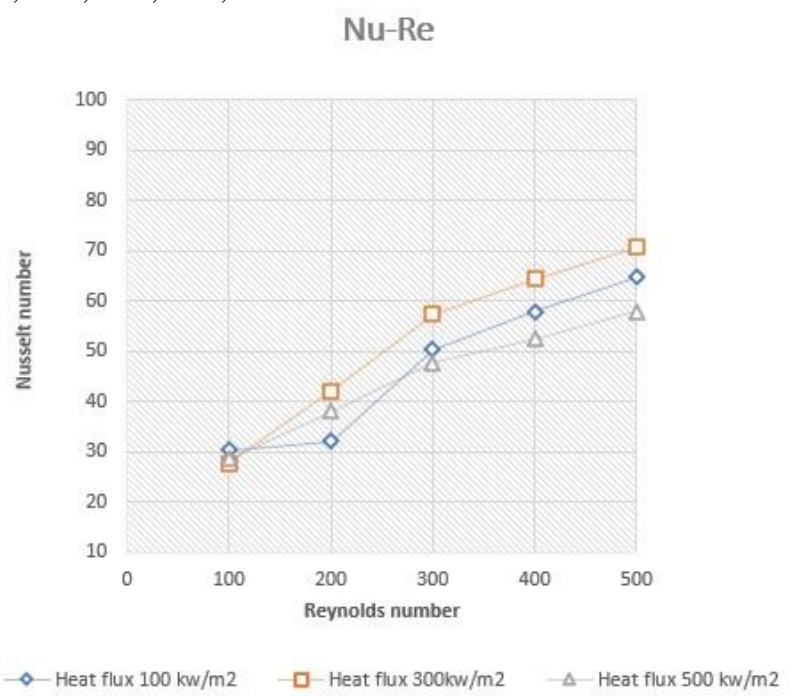

Figure No.10: Variation of Nusselt number and Reynolds number of triangular fins at three heat flux values of 100, 300, $500 \mathrm{kw} / \mathrm{m} 2$ respectively.

Simulations were performed for the triangular fins and the graphs are generated for five values of Reynolds numbers i.e., $100,200,300,400,500$ and five values of Nusselt numbers of present results at Heat flux 100, 300 and $500 \mathrm{kw} / \mathrm{m} 2$ respectively.

The above are the results for the triangular fins whose angle is 63.068 degrees. Now, we will consider the two more triangles whose angles are 60 and 65 degrees.

\section{At 60 degrees angle:}

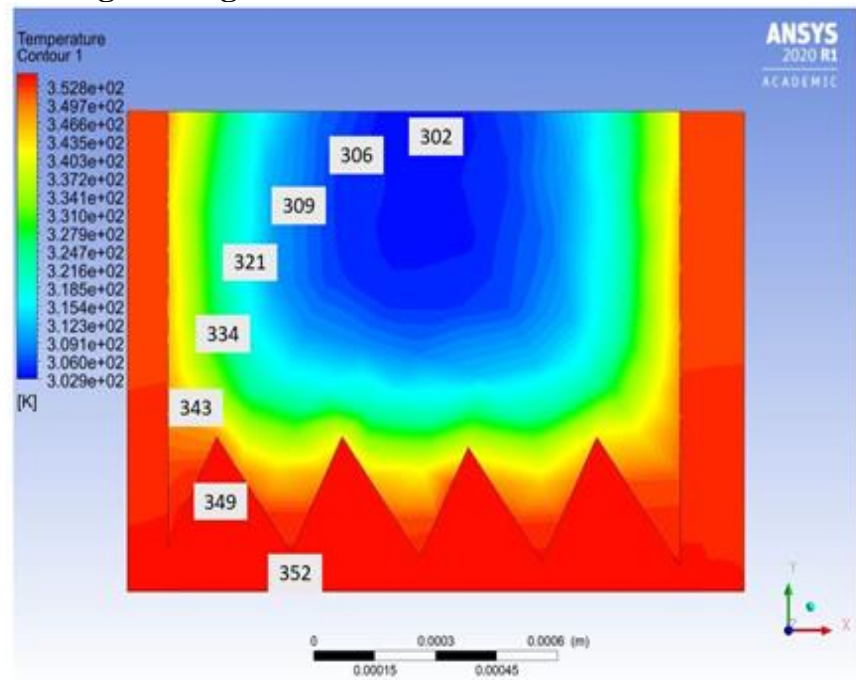

Figure No.11: Temperature contour of triangular fins whose angle is 60 degrees.

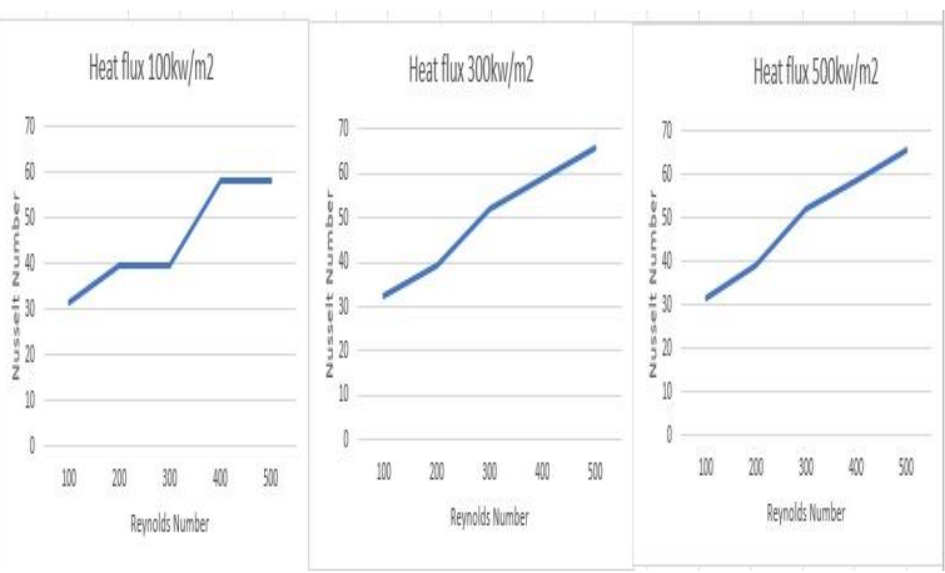

Figure No.12: Variation of Nusselt number and Reynolds number of triangular fins at three heat flux values of 100, 300 and $500 \mathrm{kw} / \mathrm{m} 2$ respectively.

Simulations were performed for the triangular fins and the graphs are generated for five values of Reynolds numbers i.e., 100, 200, 300, 400, 500 and five values of Nusselt numbers of present results of angle 60 degrees at Heat flux 100, 300 and $500 \mathrm{kw} / \mathrm{m} 2$ respectively.

\section{At 65 degrees angle:}

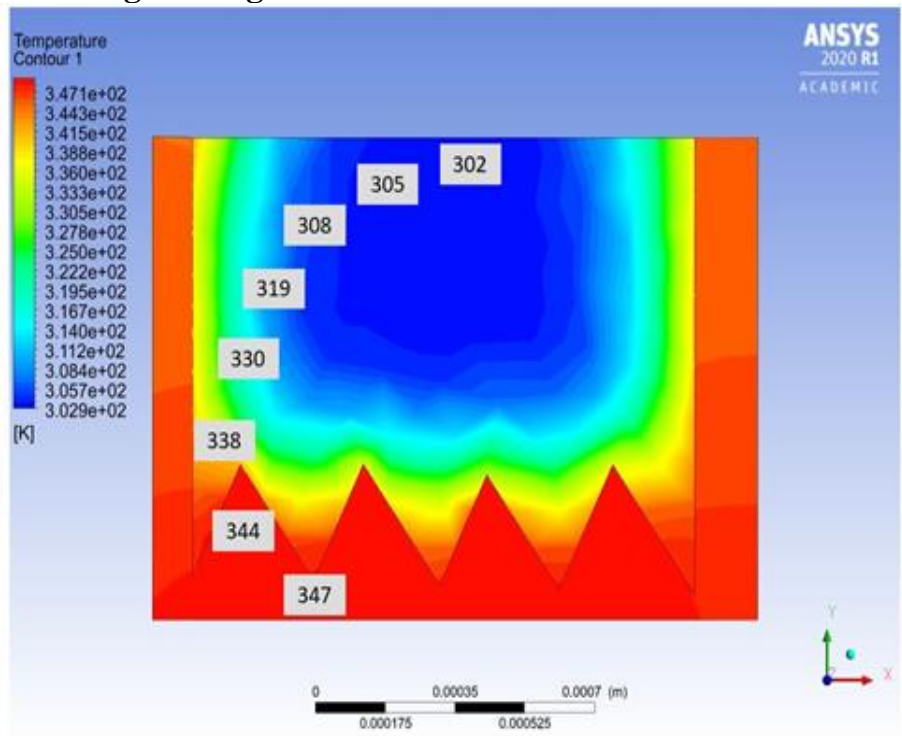

Figure No.13: Temperature contour at 65 degrees angle of triangle. 
International Journal of Engineering Applied Sciences and Technology, 2020

Vol. 5, Issue 4, ISSN No. 2455-2143, Pages 310-318

Published Online August 2020 in IJEAST (http://www.ijeast.com)

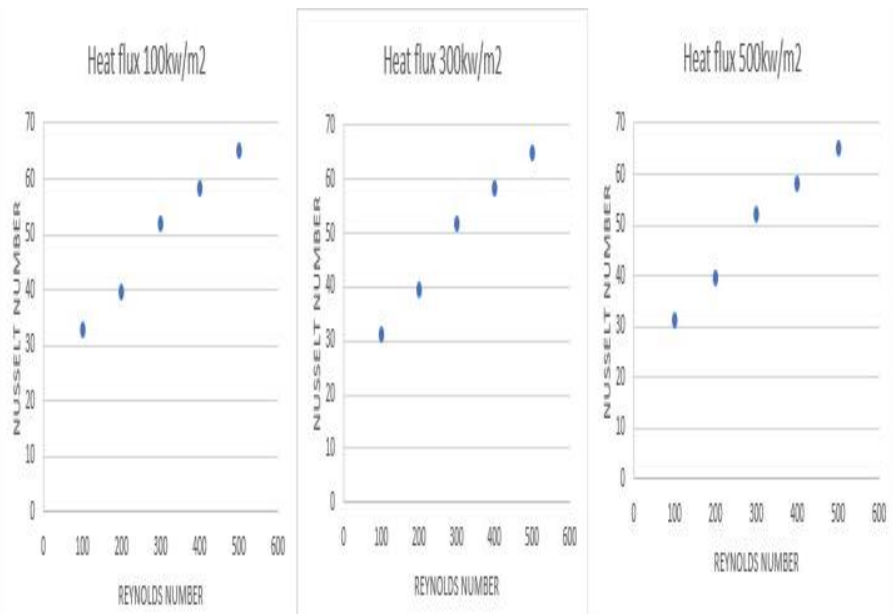

Figure No.14: Variation of Nusselt number and Reynolds number of triangular fins at three heat flux values of 100, 300 and $500 \mathrm{kw} / \mathrm{m} 2$ respectively.

Simulations were performed for the triangular fins and the graphs are generated for five values of Reynolds numbers i.e., $100,200,300,400,500$ and five values of Nusselt numbers of present results of angle 65 degrees at Heat flux 100, 300 and $500 \mathrm{kw} / \mathrm{m} 2$ respectively.

\section{Validation of the model}

For the purpose of validation, Results from Yogesh $\mathrm{K}$ Prajapati are reproduced using the same way of approach.

Geometry has been considered which consists of a microchannel with rectangular fins with dimensions of Length: $3.7 \mathrm{~mm}$, Height: $1.1 \mathrm{~mm}$, Fin Height: $0.6 \mathrm{~mm}$, Fin Width: $0.5 \mathrm{~mm}$

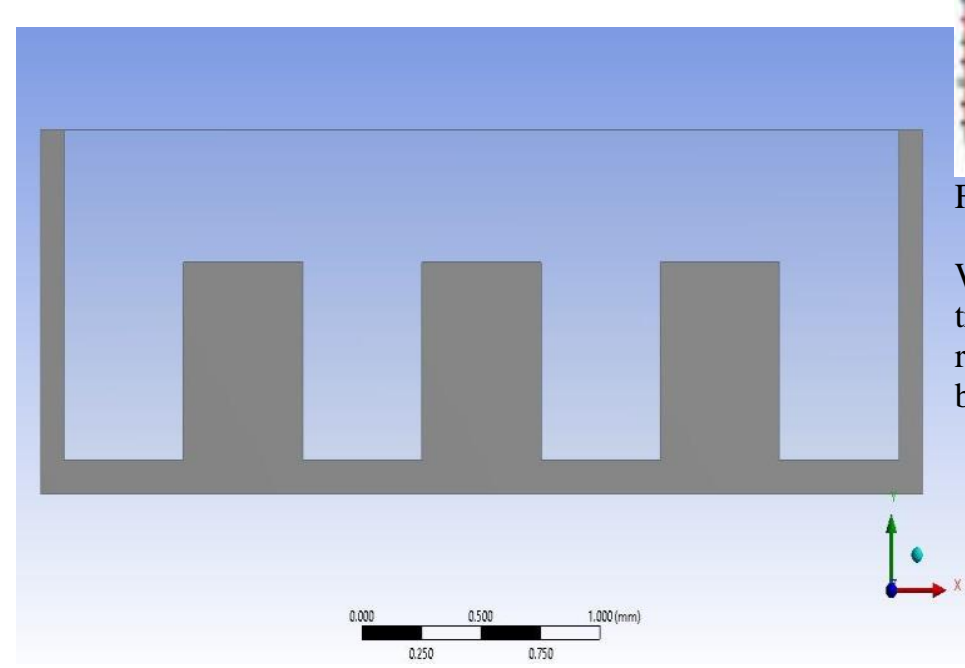

Figure No.15: Micro-channel Heat Exchanger with rectangular fins.

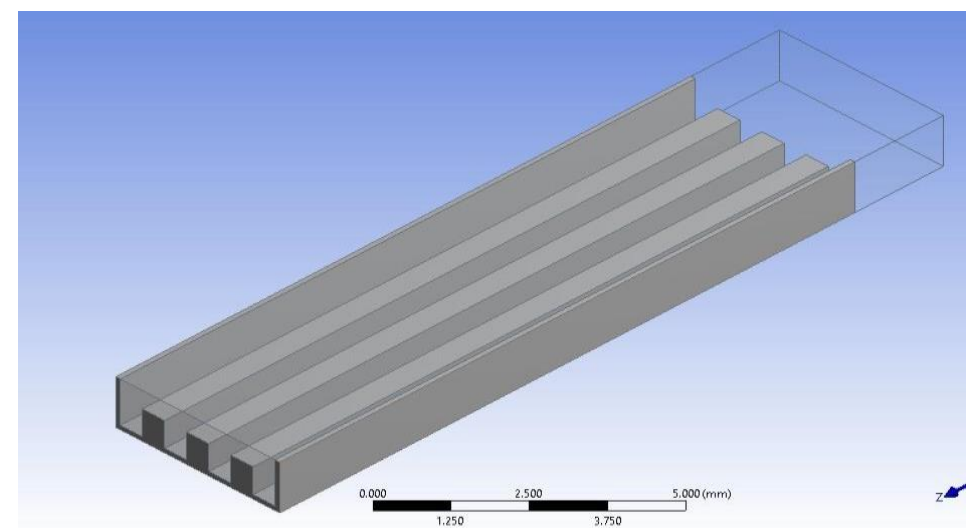

Figure No. 16: Isometric view of a Micro-channel Heat Exchanger with rectangular fins.

The boundary conditions considered are uniform heat flux at the bottom wall and all other walls remain adiabatic whereas inlet temperature is $303 \mathrm{k}$ and Reynolds number is between $100-500$.

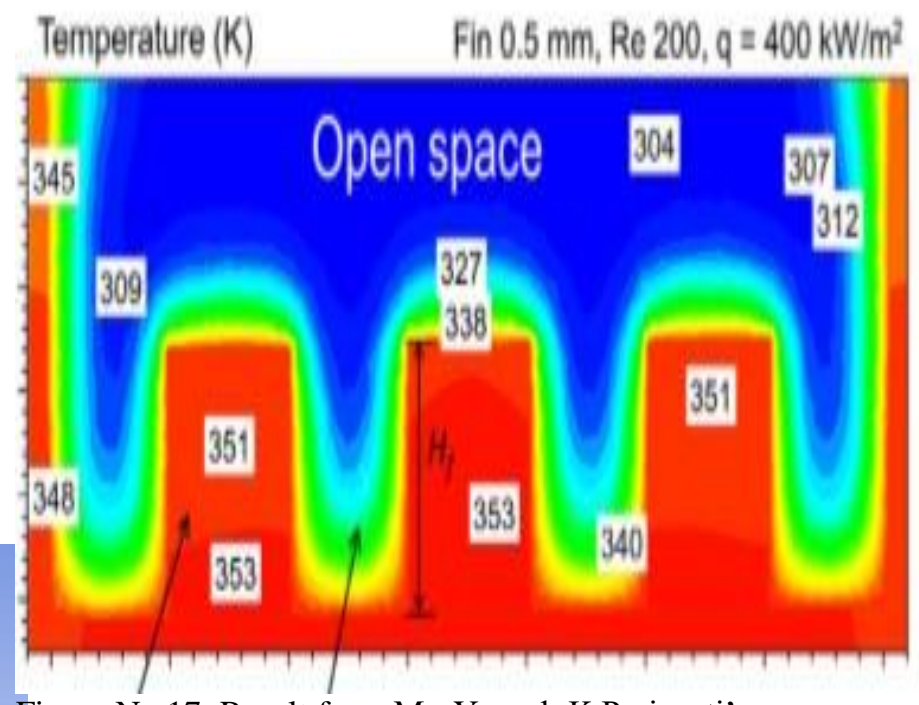

Figure No.17: Result from Mr. Yogesh K Prajapati’s paper.

We have now replaced these rectangular fins with the above triangular fins and the results are compared between rectangular fins and triangular fins to see the difference between them. 


\section{REYNOLDS NUMBER 200}

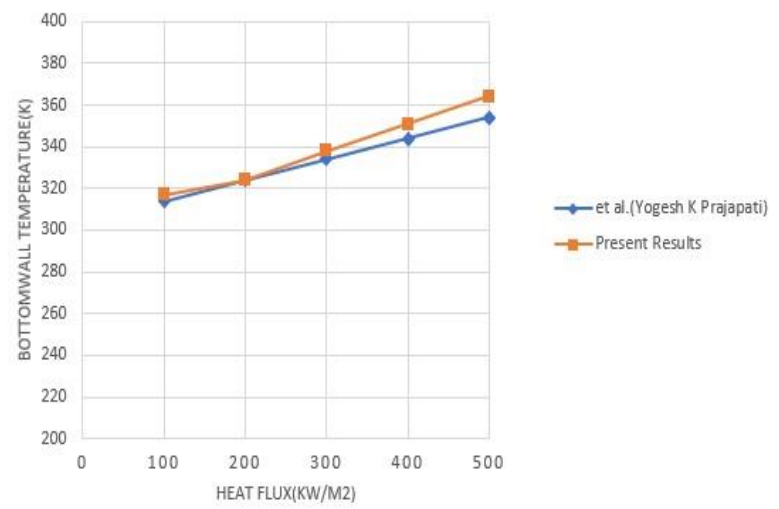

Figure No.18: Comparison between the bottom wall temperature and heat flux at Reynold number 200 for rectangular and triangular fins.

Simulations were performed for the rectangular fins and triangular fins and the graphs are generated for five values of Heat fluxes i.e., 100, 200, 300, 400, 500 and five values of Bottom wall temperatures at et al. (Yogesh K Prajapati) and triangular fins at Reynolds number 200.

\section{REYNOLDS NUMBER 300}

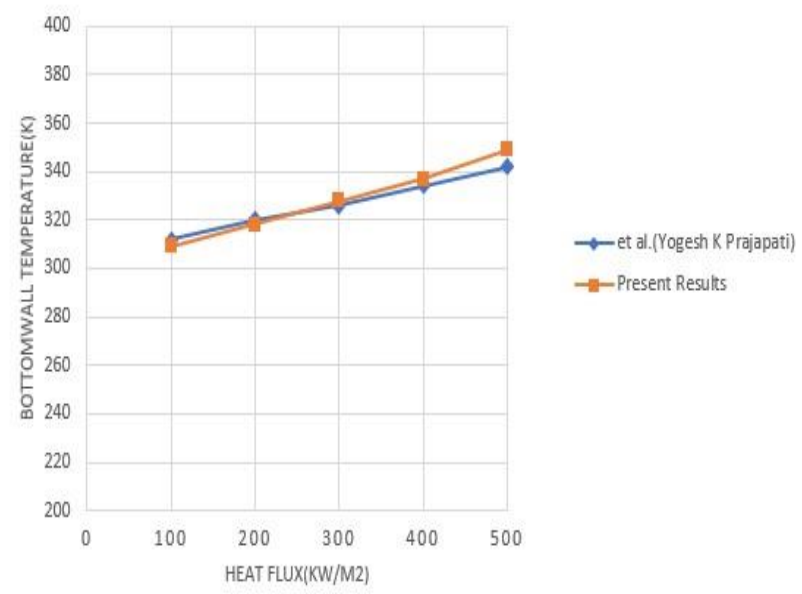

Figure No.19: Comparison between the bottom wall temperature and heat flux at Reynold number 300 for rectangular and triangular fins.

Simulations were performed for the rectangular fins and triangular fins and the graphs are generated for five values of Heat fluxes i.e., 100, 200, 300, 400, 500 and five values of Bottom wall temperatures at et al. (Yogesh K Prajapati) and triangular fins at Reynolds number 300.

\section{HEAT FLUX $300 \mathrm{KW} / \mathrm{M} 2$}

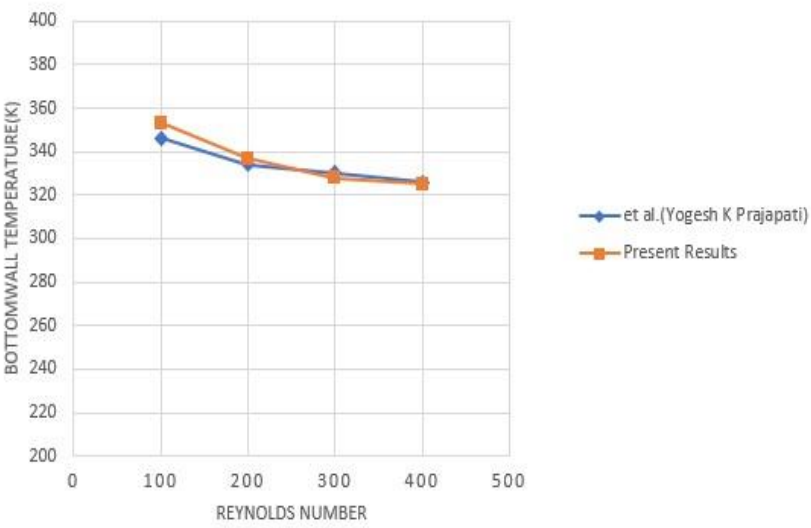

Figure No.20: Comparison between bottom wall temperature and Reynolds number at heat flux $300 \mathrm{kw} / \mathrm{m} 2$ for rectangular and triangular fins.

Simulations were performed for the rectangular fins and triangular fins and the graphs are generated for five values of Reynolds numbers i.e., 100, 200, 300, 400, 500 and five values of Bottom wall temperatures at et al. (Yogesh $\mathrm{K}$ Prajapati) and triangular fins at Heat flux $300 \mathrm{kw} / \mathrm{m} 2$.

\section{HEAT FLUX $500 \mathrm{KW} / \mathrm{M} 2$}

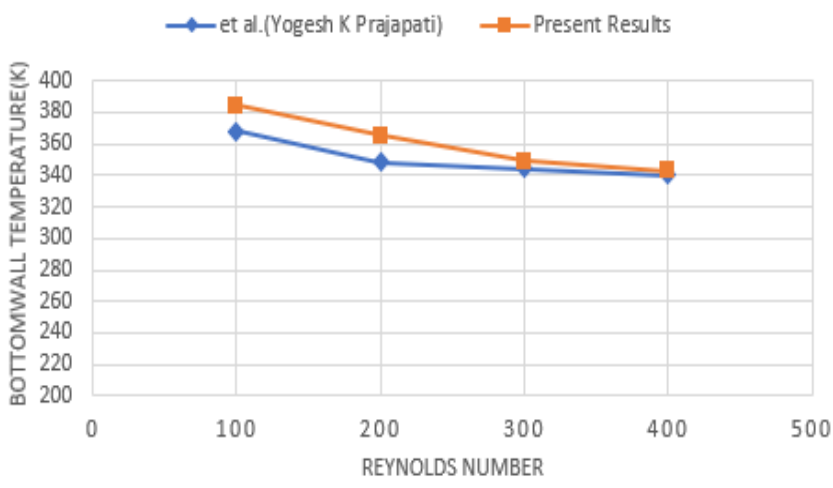

Figure No.21: Comparison between bottom wall temperature and Reynolds number at heat flux $500 \mathrm{kw} / \mathrm{m} 2$ for rectangular and triangular fins.

Simulations were performed for the rectangular fins and triangular fins and the graphs are generated for five values of Reynolds numbers i.e., 100, 200, 300, 400, 500 and five values of Bottom wall temperatures at et al. (Yogesh $\mathrm{K}$ Prajapati) and triangular fins at Heat flux $500 \mathrm{kw} / \mathrm{m} 2$. 


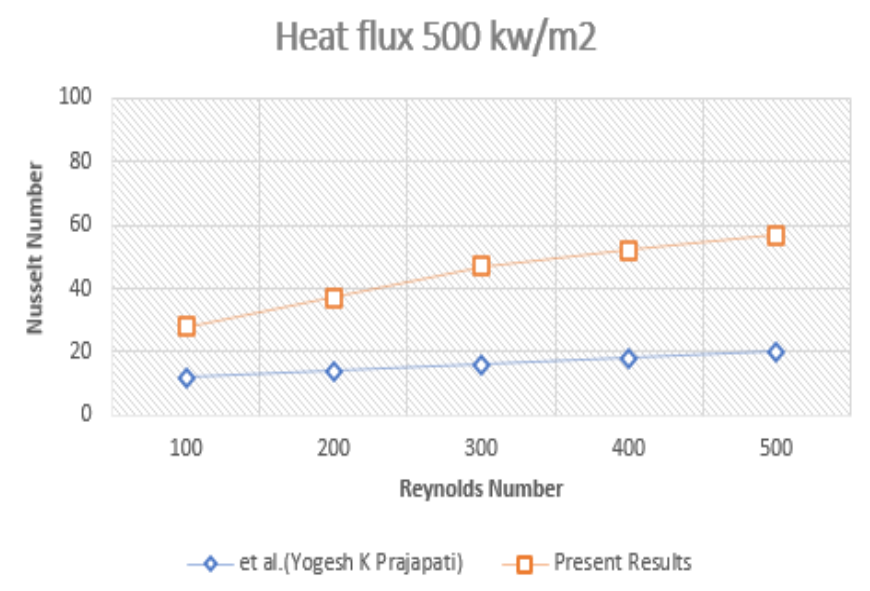

Figure No.22: Comparison between Nusselt number and Reynolds number at heat flux $500 \mathrm{kw} / \mathrm{m} 2$ for rectangular and triangular fins.

Simulations were performed for the rectangular fins and triangular fins and the graphs are generated for five values of Reynolds numbers i.e., 100, 200, 300, 400, 500 and five values of Nusselt numbers at et al. (Yogesh K Prajapati) and triangular fins at Heat flux $500 \mathrm{kw} / \mathrm{m} 2$.

We observed that the results of triangular fins are comparatively higher than rectangular fins. Thus, we can make use of triangular fins also for a microchannel heat exchanger.

\section{OPTIMIZATION}

For the optimization of our model, we have performed a optimization technique i.e., Taguchi Method for which we have considered nine set of experiments to check which experiment is optimum.

For this process, we consider three controllable factors like Reynolds number, Heat flux $(\mathrm{kw} / \mathrm{m} 2)$, Angle of triangle(degrees) and two uncontrollable factors like Nusselt number and Temperature(k) from our experiment.

Table No. 01: Factors taken for optimization. Reynolds Number Heat flux (kw/m2) Angle of triangle(degrees'

\begin{tabular}{c|c|c|}
\hline 100 & 100 & 60 \\
\hline 300 & 300 & 63.068 \\
\hline 500 & 500 & 65 \\
\hline
\end{tabular}

We will take a set of nine experiments for performing optimization and obtain a single set of values that are optimum for our experiment.
Table No. 02: Design of experiments generated using Taguchi Method.

\begin{tabular}{r|r|r|r|r|}
\hline Reynolds Number & Heat flux(kw/m2) & Angle & Nusselt Number & Temperature(K) \\
\hline 100 & 100 & 60.000 & 58.30 & 311 \\
\hline 100 & 300 & 63.068 & 70.58 & 322 \\
\hline 100 & 500 & 65.000 & 65.14 & 338 \\
\hline 300 & 100 & 63.068 & 64.68 & 310 \\
\hline 300 & 300 & 65.000 & 65.14 & 324 \\
\hline 300 & 500 & 60.000 & 65.88 & 338 \\
\hline 500 & 100 & 65.000 & 65.15 & 310 \\
\hline 500 & 300 & 60.000 & 65.88 & 324 \\
\hline 500 & 500 & 63.068 & 57.83 & 340 \\
\hline & & & & \\
\hline
\end{tabular}

We will consider the temperature to be less and Nusselt number to be high for $\mathrm{S} / \mathrm{N}$ ratios in our optimization process as per the instructions and we will generate signal to noise ratio plots. Signal to noise ratio(S/N) is defined as ratio of the level of a desired signal to the level of background noise.

The generated $\mathrm{S} / \mathrm{N}$ ratio plots are as shown below.

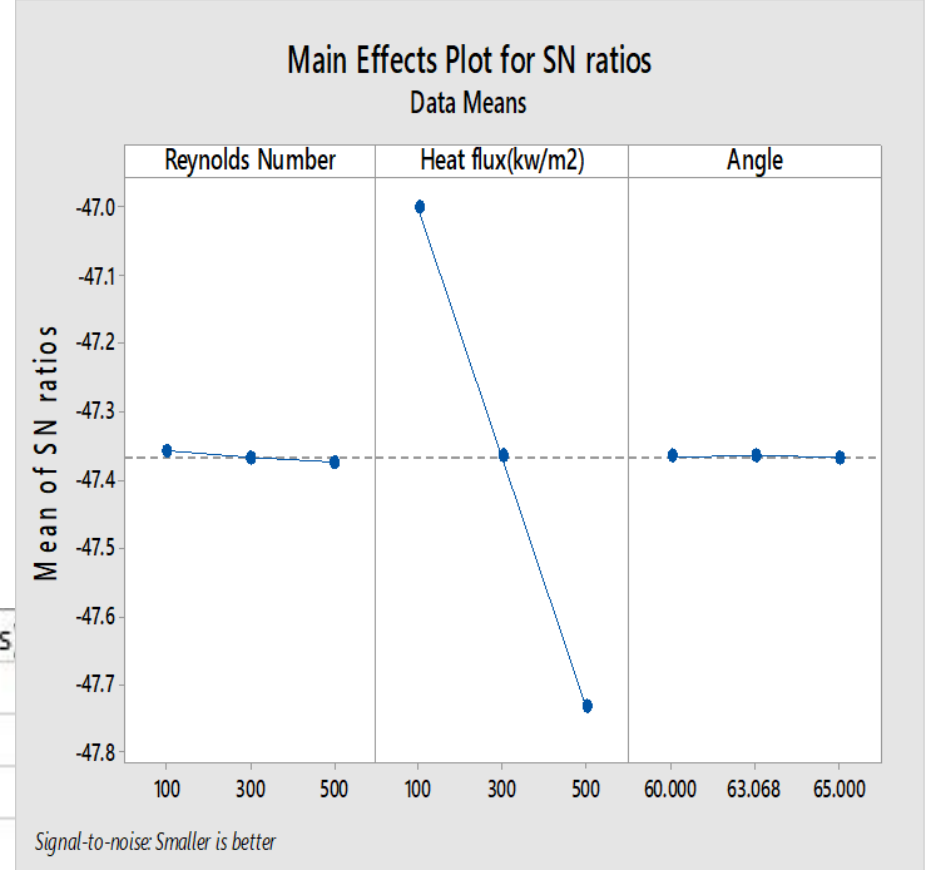

Figure No.23: Signal to Noise Ratio plot for temperature. 


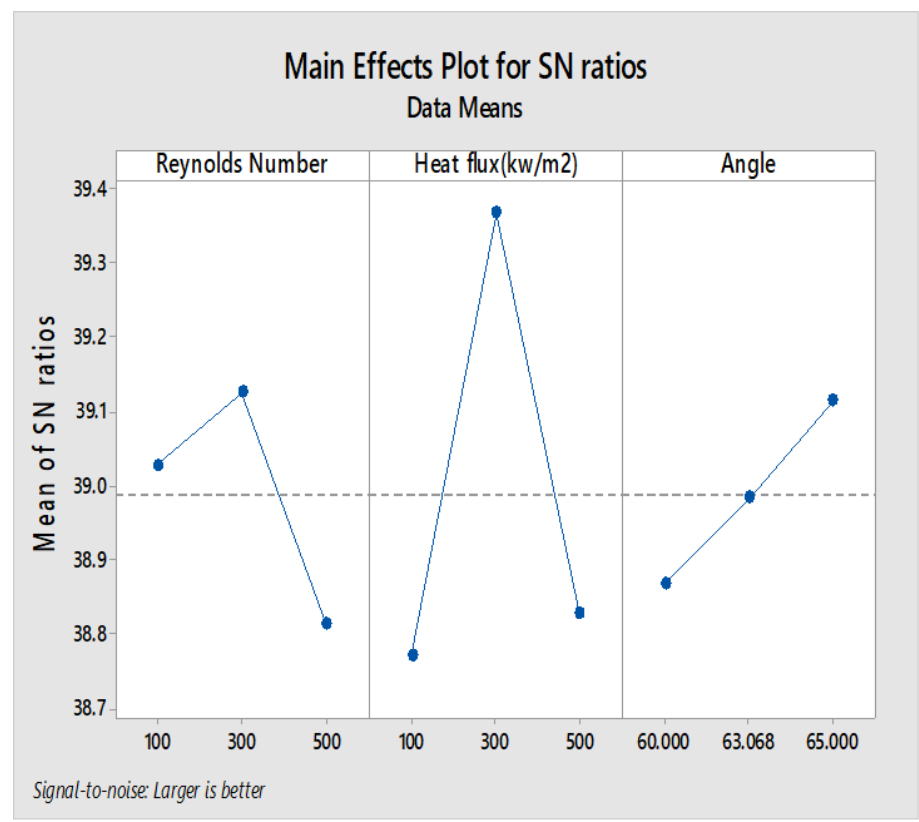

Figure No.24: Signal to Noise Ratio plot for Nusselt Number.

From the above generated graphs, we see that the maximum values of Nusselt number arrived at heat flux of $300 \mathrm{kw} / \mathrm{m} 2$, Reynolds number of 300 and angle of triangle of 65 degrees and this is the fifth experiment in our set of nine experiments considered. Hence, these are our optimum values.

\section{CONCLUSION}

Micro-channel Heat Exchangers are allowing for the event of a full new class of economical and low impact product for air conditioning units, refrigeration systems, transport cooling and alternative cooling applications. By employing a Microchannel device, a cooling system needs less refrigerant, less weight, less area and fewer energy. Heat transfer gets reduced if any air gaps are within the device but once a Micro-channel device is employed it improves the warmth transfer as all the elements of it are brazed along leading to no air gaps. Fins are the extended surfaces that are helpful in increasing heat transfer rate as they are having sensible importance in ensuing most heat flow per unit mass with simple producing. As we know that both rectangular fins and triangular fins are straight fins. Triangular fins are attractive for their shape and also, we observed that performance values are high for a triangular fin when compared to rectangular fin from our experiment. So, we can replace the rectangular fins with triangular fins for our equipment as triangular fins are engaging as for identical quantity of warmth transfer, it needs abundant lesser volume than the oblong fins and this will also result in reduced usage of raw material, less transport cost, less storage space. Hence, we can say that using triangular fins can be beneficial for a manufacturer.

\section{REFERENCE}

1. Yogesh Prajapati K (2019). Influence of fin height on heat transfer and fluid flow characteristics of a rectangular microchannel heat sink in International Journal of Heat and Mass Transfer, (pp 1041-1052)

2. Nor Haziq Naqiuddin, Lip Huat Saw, Ming Chian Yew, Farazila Yusof, Hiew Mun Poon, Zuansi Cai and Hui San Thiam (2018). Numerical investigation for optimizing segmented micro-channel heat sink by Taguchi-Grey method in Applied Energy, (pp 437450)

3. Nor Haziq Naqiuddin, Lip Huat Saw, Ming Chian Yew, Ming Kun Yew and Farazila Yusof (2017). Numerical study of the geometrically graded microchannel heat sink for high heat flux application in Applied Energy, (pp 4016-4021)

4. Alireza Moradikazerouni, Masoud Afrand, Jalal Alsarraf, Omid Mahian, Somchai, Wongwises and Minh-Duc Tran (2019). Comparison of the effect of five different entrance channel shapes of a microchannel heat sink in forced convection with application to cooling a supercomputer circuit board in Applied Thermal Engineering, (pp 1078-1089)

5. Nouman Ali, Hassan Nazir and Majid Ali (2017). Designing of compact rectangular microchannel heat exchanger based on thermal resistance network for waste heat recovery systems in International Conference on Energy Conservation and efficiency, (NanoSET-2017)

6. William C. Yameen, Nathan A. Piascik, Riccardo C. Clemente, Andrew K. Miller, Seyed A. Niknam, Jingru Benner, Anthony D. Santamaria and Mehdi Mortazavi (2019). Experimental Characterization of a Manifold-Microchannel Heat Exchanger Fabricated Based on Additive Manufacturing in Intersociety Conference on Thermal and Thermomechanical Phenomena in Electronic Systems, (DOI:10.1109/ITHERM.2019.8757306)

7. Stăncuţ Eugenia, Cernăianu Corina and Popescu Daniela (2016). Experimental study in cooling microprocessors with microchannel heat exchanger in International Conference on Applied and Theoretical Electricity, (ICATE 2016)

8. Gábor Takács, György Bognár, Enikő Bándy, Gábor Rózsás and Péter G. Szabó (2017). Fabrication and characterization of microscale heat sinks in Microelectronics reliability, (pp 480-487) 
9. Samuel D. Marshall, Rerngchai Arayanarakool, Lakshmi Balasubramaniam, Bing Li, Poh Seng Lee and Peter C. Y. Chen (2017). Heat exchanger improvement via curved, angular and wavy microfluidic channels: A comparison of numerical and experimental results in Intersociety Conference on Thermal and Thermomechanical Phenomena in ElectronicSystems,

(DOI:10.1109/ITHERM.2017.7992539)

10. Aik Ling Goh, Kim Tiow Ooi and Ulrich Stimming (2014). Nature-inspired enhanced microscale heat transfer in macro geometry in Intersociety Conference on Thermal and Thermomechanical Phenomena in Electronic Systems, (DOI:10.1109/ITHERM.2014.6892308)

11. Nor Haziq Naqiuddin, Lip Huat Saw, Ming Chian Yew, Farazila Yusof, Tan Ching Ng and Ming Kun Yew (2017). Overview of micro-channel design for high heat flux application in Renewable and Sustainable Energy Reviews, (pp 901-914)

12. Xiao-Hu Yang, Si-Cong Tan, Yu-Jie Ding and Jing Liu (2017). Flow and thermal modeling and optimization of micro/mini-channel heat sink in Applied Thermal Engineering, (pp 289-296)

13. Murat Parlak, Özge Östürk, Ümit N. Temel and Kerim Yapici (2017). Heat transfer performance of water-based nanofluids containing various types of metal oxide nanoparticles in an air-cooled microchannel heat exchanger in Intersociety Conference on Thermal and Thermomechanical Phenomena in Electronic Systems, (DOI:10.1109/ITHERM.2017.7991849)

14. Serhii V. Oleksiienko, Oleh O. Novomlynets and Svitlana M. Yushchenko (2016). Diffusion bonding technique concerning the production of microchannel heat exchangers in International Conference on Electronics and Nanotechnology, (DOI:10.1109/ELNANO.2016.7493009)

15. Yanhui Han, Yan Liu, Ming Lia and Jin Huang (2011). A review of development of micro channel heat exchanger applied in air-conditioning system in $20112^{\text {nd }}$ International Conference on Advances in EnergyEngineering, (DOI:10.1016/j.egypro.2011.12.910) 